\title{
Saharan dust as a causal factor of significant cloud cover along the Saharan Air Layer in the Atlantic Ocean
}

\author{
Pavel Kishcha ${ }^{1}$, Arlindo M. da Silva ${ }^{2}$, Boris Starobinets ${ }^{I}$, and Pinhas Alpert ${ }^{1}$ \\ ${ }^{1}$ Department of Geosciences, Tel-Aviv University, Tel-Aviv, Israel \\ pavel@cyclone.tau.ac.il \\ ${ }^{2}$ Global Modeling and Assimilation Office, NASA/GSFC, Greenbelt, Maryland, USA
}

\begin{abstract}
The tropical Atlantic is frequently affected by Saharan dust intrusions. Based on MODIS cloud fraction (CF) data during the ten-year study period, we found that these dust intrusions contribute to significant cloud cover along the Saharan Air Layer (SAL). Below the temperature inversion at the SAL's base, the presence of large amounts of settling dust particles, together with marine aerosols, produces meteorological conditions suitable for the formation of shallow stratocumulus clouds. The significant cloud fraction along the SAL together with clouds over the Atlantic Intertropical Convergence Zone contributes to the 20\% hemispheric CF asymmetry between the tropical North and South Atlantic. This leads to the imbalance in strong solar radiation, which reaches the sea surface between the tropical North and South Atlantic, and, consequently, affects climate formation in the tropical Atlantic. Therefore, despite the fact that, over the global ocean, there is no noticeable hemispheric asymmetry in cloud fraction, over the significant area such as the tropical Atlantic the hemispheric asymmetry in CF takes place. Saharan dust is also the major contributor to hemispheric aerosol asymmetry over the tropical Atlantic. The NASA GEOS-5 model with aerosol data assimilation was used to extend the MERRA reanalysis with five atmospheric aerosol species (desert dust, sulfates, organic carbon, black carbon, and sea-salt). The obtained ten-year (2002 - 2012) MERRA-driven aerosol reanalysis dataset (aka MERRAero) showed that, over the tropical Atlantic, dust and carbonaceous aerosols were distributed asymmetrically relative to the equator, while other aerosol species were distributed more symmetrically.
\end{abstract}

Reference: Kishcha, P., da Silva, A., Starobinets, B., and Alpert, P. (2016). Saharan dust as a causal factor of significant cloud cover along the Saharan Air Layer in the Atlantic Ocean. In: Air Pollution Modeling and its Applications XXIV, Chapter 92, Springer, DOI 10.1007/978-3-31924478-5_92, $569-573$.

\section{Introduction}

The NASA GEOS-5 modeled aerosol data set (aka MERRAero) was used in the current study in order to estimate the contribution of different aerosol species to hemispheric aerosol asymmetry over the tropical Atlantic Ocean. GEOS-5 includes a module representing atmospheric aerosols (Colarco et al., 2010). This aerosol module is based on a version of the Goddard Chemistry, Aerosol, Radiation, and Transport (GOCART) model (Chin et al., 2002). GOCART treats the sources, sinks, and chemistry of desert dust; sulfate; sea salt; black carbon and organic carbon aerosols. Both dust and sea salt have wind-speed dependent emission functions, while sulfate and carbona- 
ceous species have emissions principally from fossil fuel combustion, biomass burning, and biofuel consumption, with additional biogenic sources of organic carbon. An important feature of GEOS-5 is including aerosol data assimilation using aerosol optical thickness (AOT) retrieved from MODIS instruments on board the NASA Terra and Aqua satellites. Our main point is that, over the tropical Atlantic, not only is Saharan dust responsible for the pronounced hemispheric aerosol asymmetry, but it also contributes to significant cloud cover along the Saharan Air Layer (Kishcha et al., 2014, 2015). Over the tropical Atlantic in July, along the Saharan Air Layer, MODIS cloud fraction (CF) data showed cloud cover up to $0.8-0.9$. This cloud fraction along the SAL together with clouds over the Atlantic Inter-tropical Convergence Zone contributes to the hemispheric CF asymmetry between the tropical North and South Atlantic. This leads to the imbalance in strong solar radiation, which reaches the sea surface between the tropical North and South Atlantic, and, consequently, affects climate formation in the tropical Atlantic.

\section{Method}

As discussed by Kishcha et al. (2014, 2015), meridional distribution of modeled total AOT and AOT of various aerosol species, zonal averaged over the tropical Atlantic $\left(30^{\circ} \mathrm{N}-30^{\circ} \mathrm{S}\right)$, was used to estimate the contribution of various aerosol species to hemispheric aerosol asymmetry over the tropical Atlantic. For the purpose of comparing meridional distribution of cloud fraction with that of AOT during the same 10-year period (July 2002 - June 2012), Collection 5.1 of MODIS-Terra L3 monthly daytime cloud fraction (CF) data, with horizontal resolution $1^{\circ} \times 1^{\circ}$ was used. Furthermore, to analyze meridional rainfall distribution, the Tropical Rainfall Measuring Mission (TRMM) monthly $0.25^{\circ} \times 0.25^{\circ}$ Rainfall Data Product (3B43 Version 7) was used.

\section{Results and discussion}

The obtained results are described in detail by Kishcha et al. $(2014,2015)$. With respect to different oceans, only over the Atlantic Ocean did MERRAero demonstrate that desert dust dominated all other aerosol species and was responsible for hemispheric aerosol asymmetry there. MERRAero showed that, over the tropical Atlantic, dust and carbonaceous aerosols were distributed asymmetrically relative to the equator, while other aerosol species were distributed more symmetrically (Kishcha et al, 2014, 2015).

MERRAero showed that there are strong seasonal variations of hemispheric aerosol asymmetry. Hemispheric aerosol asymmetry is most pronounced during the season from March to July, when large amounts of Saharan dust are transported across the Atlantic (Fig. 1a). Saharan dust dominates other aerosol species over the tropical North Atlantic (Fig. 1a). Dust AOT, averaged separately over the tropical North Atlantic, is one order of magnitude higher than dust AOT averaged over the tropical South Atlantic (Kishcha et al., 2014, 2015). Therefore, dust is the major contributor to hemispheric aerosol asymmetry over the tropical Atlantic, based on GEOS-5 modeling. In September and October, when the dust contribution to total AOT decreases, we have a completely different picture: there is no noticeable hemispheric asymmetry in total AOT between the tropical North and South Atlantic Oceans (Fig. 1b). This is because the contribution of carbonaceous aerosols to total AOT in the South Atlantic is approximately equal to the contribution of dust to total AOT in the tropical North Atlantic (Fig. 1b).

With respect to meridional distribution of cloud fraction, Fig. 1c illustrate that, during the season of pronounced hemispheric aerosol asymmetry, there is hemispheric asymmetry in CF. During 
the season with no noticeable aerosol asymmetry, there is no noticeable hemispheric asymmetry in CF (Fig. 1d). Therefore, over the tropical Atlantic, hemispheric asymmetry in aerosols is accompanied by hemispheric asymmetry in cloud cover (Kishcha et al., 2015), in contrast to the situation over the global ocean (Kishcha et al., 2009).

In each month of the year, the main CF maximum coincides with the Inter-Tropical Convergence Zone (ITCZ), which is characterized by intensive rainfall (Fig. $1 \mathrm{c}$ and d). In the summer months (when pronounced hemispheric dust asymmetry was observed), MODIS CF data showed significant CF (up to 0.8) to the north from the main CF maximum, over the latitudes of transatlantic dust transport within the Saharan Air Layer (SAL) (Fig. 1c). The GEOS-5 model data showed that the significant CF to the north of the Atlantic ITCZ could be associated with the maximum in dust AOT over the latitudes of the Saharan Air Layer (SAL), between approximately $12^{\circ} \mathrm{N}$ and $24^{\circ} \mathrm{N}$ in the North Atlantic (Fig. 1 a and c). The significant cloud fraction along SAL, together with clouds over the Atlantic ITCZ, contributes to hemispheric asymmetry in CF over the tropical Atlantic. In July, CF averaged separately over the tropical North Atlantic is $20 \%$ higher than that averaged over the tropical South Atlantic. This leads to the imbalance in strong solar radiation reaching the sea surface between the tropical North and South Atlantic and affects climate formation in the tropical Atlantic.
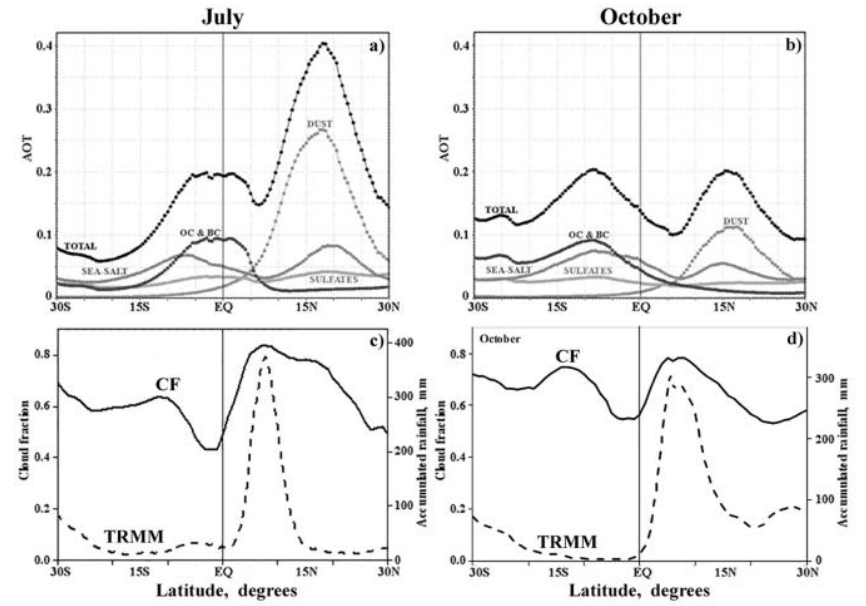

Figure 1. Comparisons between meridional distribution of AOT/CF/TRMM rainfall during (a and c) the season of pronounced hemispheric aerosol asymmetry and (b and d) during the season with no noticeable hemispheric aerosol asymmetry.

Kishcha et al. (2015) showed that the ocean area of SAL with Saharan dust transported across the Atlantic is covered by significant cloudiness up to $0.8-0.9$. The area of SAL with significant $\mathrm{CF}$ is characterized by limited precipitation. This indicates that clouds along the SAL are not developed enough. The temperature inversion below the SAL base prevents deep cloud formation; this explains limited precipitation in these zones. On the other hand, meteorological conditions below the temperature inversion at the SAL base include significant atmospheric humidity and the presence of large amounts of settling dust particles together with marine aerosols. As known, aerosol species often combine to form mixed particles, with properties different from those of their components (Andreae et al., 2009). Mineral dust particles are known to be not very efficient cloud condensation nuclei $(\mathrm{CCN})$, unless they are coated with soluble materials (Andreae et al., 2009). 
Using airplane measurements, Levin et al. (2005) showed that dust transport over the sea could lead to sea-salt coating on dust particles. Coating settling dust particles with sea-salt could modify them into efficient $\mathrm{CCN}$. Being below the temperature inversion and acting as efficient $\mathrm{CCN}$, Saharan dust particles coated with sea-salt contribute to the formation of shallow stratocumulus clouds. This physical mechanism, based on the influence of Saharan dust on stratocumulus clouds below the temperature inversion, could explain the observed significant cloud cover (CF up to 0.8 - 0.9) along the Saharan Air Layer (Kishcha et al., 2015).

Kishcha et al. (2015) analyzed possible relationships between properties of clouds in the area of SAL and those of Saharan dust, using MODIS L3 gridded monthly data $\left(1^{\circ} \times 1^{\circ}\right)$ of the effective radius of cloud droplets for liquid water clouds. They found that the effective radius of cloud droplets increases with distance from the Sahara. This can be explained by the decrease in CCN numbers associated with the decreasing numbers of settling Saharan dust particles with distance from the Sahara, in accordance with the observed decrease in dust AOT. This relationship supports the above-mentioned physical mechanism of cloud formation below the SAL's base.

\section{References}

Chin M, Ginoux P, Kinne S, Torres O, Holben B, Duncan BN, Martin RV, Logan J, Higurashi A, Nakajima T (2002) Tropospheric aerosol optical thickness from the GOCART model and comparisons with satellite and sun photometer measurements. J Atmos Phys 59: 461-483

Colarco P, da Silva A, Chin M, Diehl T (2010) Online simulations of global aerosol distributions in the NASA GEOS-4 model and comparisons to satellite and ground-based aerosol optical depth. J Geophys Res 115: D14207. doi:10.1029/2009JD012820

Kishcha P, Starobinets B, Kalashnikova O, Long CN, Alpert P (2009) Variations in meridional aerosol distribution and solar diming. J Geophys Res 114: D00D14. doi 10.1029/2008JD010975

Kishcha P, da Silva A, Starobinets B, Long CN, Kalashnikova O, Alpert P (2014) Meridional distribution of aerosol optical thickness over the tropical Atlantic Ocean. Atmos Chem Phys Discuss 14: 23309-23339. doi:10.5194/acpd-14-23309-2014

Kishcha P, da Silva A, Starobinets B, Long CN, Kalashnikova O, Alpert P (2015) Saharan dust as a causal factor of hemispheric asymmetry in aerosols and cloud cover over the tropical Atlantic Ocean. International Journal of Remote Sensing: http://dx.doi.org/10.1080/01431161.2015.1060646 (in print)

Andreae MO, Hegg DA, Baltensperger U (2009) Sources and nature of atmospheric aerosols. In:Levin Z and Cotton W (ed) Aerosol pollution impact on precipitation, Springer, Dordrecht, p 45 - 90

Levin Z, Teller A, Ganor E, Yin Y (2005) On the interactions of mineral dust, sea-salt particles, and clouds: A measurement and modeling study from the Mediterranean Israeli Dust Experiment campaign. J Geophys Res 110: D20202. doi:10.1029/2005JD005810 